\title{
Articulation Accuracy of Children Using an Electrotactile Speech Processor
}

\author{
Karyn L. Galvin, Robert S. C. Cowan, Julia Z. Sarant, Emily A. Tobey, Peter J. Blamey, \\ and Graeme M. Clark
}

\begin{abstract}
Objective: Use of wearable tactile speech perception devices is suggested to help overcome the difficulties in speech production resulting from severe and profound hearing impairment in children. This suggestion is based on the assumption that subjects can use tactile input in isolation, or in combination with information from residual aided hearing, to monitor and modify their speech. The present study evaluated the benefits to articulation provided through use of a multichannel electrotactile device ("Tickle Talker(iñ").
\end{abstract}

Design: Six profoundly hearing-impaired children were videotaped speaking with the Tickle Talker on and with the Tickle Talker off during conversations with their audiologist. Five of the subjects also wore their binaural hearing aids during all recorded conversations. The number of vowels, consonants, and overall phonemes correctly articulated by each child in the two conditions were compared.

Results: One subject improved articulation of initial consonants and initial phonemes; one subject improved articulation of total vowels, total consonants, initial consonants, total phonemes, and initial phonemes; and a third subject improved articulation of total vowels and medial phonemes.

Conclusions: Use of on-line tactile feedback from the Tickle Talker may benefit the articulation accuracy of some children, and the device may therefore be suitable to use with children who have not responded to more traditional speech training techniques.

(Ear \& Hearing 1995;16;209-219)

Numerous studies have suggested a strong link between speech perception ability and speech production skills in hearing-impaired children (Boothroyd, 1984; Geers \& Moog, 1987). The normally hearing child utilizes acoustic feedback from both

Australian Bionic Ear and Hearing Research Institute (K.L.G., J.Z.S.), East Melbourne, Australia; Cooperative Research Center for Cochlear Implant, Speech and Hearing Research (R.S.C.C., P.J.B.), East Melbourne, Australia; Department of Otolaryngology (R.S.C.C., P.J.B.), University of Melbourne, Parkville, Australia; Department of Communication Disorders (E.A.T.), Louisiana State University Medical Center, New Orleans, Louisiana; Department of Otolaryngology (G.M.C.), University of Melbourne, Parkville, Australia. their own voice and the voices of others as a guide to establishing the coordination and sequencing of movements of vocal structures required for accurate articulation (Nickerson \& Stevens, 1973). The profoundly hearing-impaired child has reduced access to this acoustic feedback, and this may impede the development of nonsegmental and segmental speech production skills (Binnie, Daniloff, \& Buckingham, 1982; McGarr \& Osberger, 1978). Frequent and consistent application of traditional methods of speech therapy may often result in improvements in intelligibility and articulation for these children. However, despite receiving therapy, many profoundly hearing-impaired children continue to develop and produce speech that differs from normal speech in a multitude of ways (Gold, 1980; Nickerson \& Stevens, 1973). For these cases reliance only on hearing aids and lipreading combined with standard speech therapy is clearly insufficient, and an alternative or supplementary approach may prove beneficial.

The use of speech-training devices in speech production therapy has been extensively examined, with the use of computer-based, visual and tactile aids being suggested (Houde \& Levitt, 1980; McGarr, Head, Friedman, Behrman, \& Youdelman, 1986). However, many of the devices developed have the disadvantage of being classroom or home-based, and can only be used for limited periods of time. In contrast, wearable speech-training devices can provide on-line feedback in daily communication. Online feedback may facilitate the improvement of speech production patterns by enabling the child to constantly self-monitor, rather than affording this opportunity only in training sessions (Houde \& Levitt, 1980). In addition, on-line feedback may increase speaker awareness of the kinesthetic sensations associated with speech production (Stratton, 1974). This increase in sensitivity may, in turn, result in carry-over of speech production improvements to nontraining and device-off conditions. Wearable speech-training devices are also more suitable for young children, who are less likely to spend time with a classroom or home-based aid, but may utilize a wearable device during normal daily activities. This is an important advantage, as young children are optimally predisposed toward the inte- 
gration of stimuli from various sensory modalities. It is assumed that this predisposition will encourage more effective use of the minimal auditory and visual cues available, and maximize the use of proprioceptive cues in the control of speech articulators (Nickerson \& Stevens, 1973).

The tactile modality has been extensively investigated as an avenue for presenting speech information through wearable devices, with most research focusing on the presentation of information for speech perception (see reviews by Lynch, Oller, \& Eilers, 1989; Reed, Durlach, Delhorne, Rabinowitz, \& Grant, 1989; Weisenberger, 1989). The use of these perceptual devices in the role of speech production training aids assumes that the devices would process the speech of the user in the same manner as the speech of others, and that the additional information provided would lead to improved speech production. However, previous research with hearing aid users has shown that, while good speech producers were nearly always good speech perceivers, good perceivers were not always good producers (Stark \& Levitt, 1974). Similarly, although subjects may clearly show benefits to speech perception from the reception and use of information provided through a tactile device, the ability of subjects to monitor and use tactually presented information about their own speech patterns cannot be assumed. It is therefore important that any tactile device be separately evaluated for speech production benefits.

Evaluations of a number of tactile devices have indicated benefits for speech production. The use of a single-channel vibrotactile aid (Tactaid I) was shown to produce qualitative changes in the speech and language of four profoundly hearing-impaired children aged 2.5-6 years old (Goldstein \& Proctor, 1985). After 10 months of training with the Teletactor and the Oregon vocoder, thirteen 3- to 6-year-old children had made phoneme and word production gains, and had generally improved their imitative and functional use of speech (Oller, Eilers, Vergara, $\&$ LaVoie, 1986). These improvements were made at a faster rate than had been shown in previous school and therapy exercises. In an extension of this study, 11 children, average age 5.3 years, demonstrated greater improvements in phonetic information in pronunciations and contrasting syllables in imitative productions than 15 control children, average age 7.3 years (Eilers, Oller, \& Vergara, 1989). A more recent study matched users of the Nucleus 22-channel cochlear implant, the Tactaid II or VII and hearing aids (Geers \& Tobey, 1992). Assessments of phonetic (imitative mode) and phonological (spontaneous mode) aspects of the 12 children's speech over 2 years showed that the Tactaid users improved in $51 \%$ of the 39 speech feature/mode/ position combinations examined-as compared with $15 \%$ for hearing aid users and $72 \%$ for cochlear implant users. It is clear from the results of these studies that the provision of tactile information over time may result in improvements in a number of aspects of speech production.

The studies discussed above evaluated use of tactile feedback by assessing the improvements in speech production which were made over the time the children used their tactile device. Maintenance of these speech production improvements may not require the presence of on-line tactile information. However, results of Waldstein's (1990) study of seven post-linguistically deafened adults indicated that on-line auditory feedback was required to accurately maintain timing of voice onset, formant frequency range, absolute duration of vowels, duration of sentences, and fundamental frequency jitter. In addition, changes in vowel acoustics and average airflow measured in a study of three adult cochlear implantees indicated that, along with long-term calibration, auditory feedback was required for additional fine tuning on an on-line basis (Svirsky, Lane, Perkell, \& Wozniak, 1992). Furthermore, in a study of speech production of children with a cochlear implant, Tobey et al. (1991) found that more centralized second formant frequencies were produced by 13 children when their speech processors were turned off, suggesting that on-line auditory feedback played a role in the accurate production of second formant frequency. The results of a fourth study were more varied, with the on-line use of auditory feedback from the cochlear implant to recalibrate the articulation of vowels being found to be particular to the individual (Richardson, Busby, Blamey, Dowell, \& Clark, 1993). Additionally, it was suggested that the on-line use of feedback may be affected by etiology, speech processing strategy, baseline speech production, and consonant environment. Nonetheless, all of these studies demonstrate that on-line auditory feedback is useful for the self-monitoring of some aspects of speech production.

The importance of on-line tactile feedback to the speech production of children using tactile devices has also been evaluated. A case study involving a 2.5-year-old using the Tactaid I reported more appropriate use of volume and vocalization when the tactile device was used (Geers, 1986). Furthermore, 25 listeners indicated that this child's recorded imitations of words matched the teacher's productions more closely when the Tactaid was on, with improvements shown in voice quality, prosody, and segmentation. Weisenberger and Kozma-Spytek (1991) evaluated the speech production of three 12-year-old, prelingually profoundly hearing-im- 
paired children using the Tacticon TC-1600. Significantly more initial consonants (for one subject) and final consonants (for another subject) were identified by 42 teachers of the deaf when the tactile device was used. When tracking session videotapes were presented, the teachers rated two of the subjects as having significantly improved the general quality of their speech and their interaction. One of these subjects was also rated as having significantly improved his vocal quality, accuracy of articulation and inclusion of initial consonants. Both of these studies indicate that on-line tactile feedback can be beneficial in the on-line self-monitoring of aspects of speech production, and not just in promoting speech developments which can be integrated into the user's speech over the long term.

A device-on/device-off comparison of speech production, such as is implemented in the present study with the multichannel electrotactile Tickle Talker, is not sensitive to changes in speech production which are maintained in the absence of on-line feedback. Evaluation of these changes requires assessments of speech production over time. However, when assessments over time are made it is often difficult to isolate the cause of any improvements shown to one factor, such as the contribution of the tactile information. This difficulty is exacerbated when a small subject group is involved, as in the present study. For these reasons, the design of this study is limited to a device-on/device-off comparison that is only intended to indicate any benefits to articulation that are reliant on the presence of on-line tactile feedback. The strong advantage of this design is that any improvements in speech production shown by the subjects in the device-on condition will clearly be due to the presence of the tactile information, as this is the only difference between the two assessment conditions.

\section{AIM}

The aim of this study was to assess the use of on-line tactile feedback provided by the University of Melbourne's multichannel electrotactile Tickle Talker as an aid to articulation accuracy. The evaluation compared the articulation accuracy in six children's conversational speech samples collected with the Tickle Talker on and with the Tickle Talker off.

\section{METhod}

\section{Device}

The Tickle Talker was designed primarily to provide improved speech perception for patients unable to benefit from or proceed with cochlear implanta- tion (Blamey \& Clark, 1985). The device has been shown to provide substantial speech perception benefits to hearing-impaired children and adults (Cowan et al., 1990, 1991). It is a battery-powered, wearable device, consisting of a lapel microphone, a speech processor and an electrode handset of four rings. Two electrodes are positioned in the sides of each ring to stimulate the digital nerve bundles in the fingers of the nondominant hand. This stimulation site provides a more pleasant sensation and a wider dynamic range than that provided by electrocutaneous stimulation of other body sites. In addition, the digital nerves provide a well-ordered spatial display of information with very high electrode position recognition scores (Blamey \& Clark, 1987).

The Tickle Talker processing hardware is based on the speech processor used with the Nucleus Minisystem-22 cochlear implant (Seligman, 1987). Speech feature information is encoded in a series of biphasic electrical pulses, and is presented as electrical parameters to the user through the eight electrodes. The device provides (i) an estimate of the fundamental frequency (F0), (ii) an estimate of the second formant frequency (F2), (iii) the amplitude of $\mathrm{F} 2$, and (iv) an indication of the presence of high frequency information above $4 \mathrm{kHz}$. F0 is electrically encoded as pulse rate, and changes in F0 are perceived by the user as altered "roughness" of stimulation. This perception of roughness provides information on syllable stress and consonant voicing. F2 is encoded and perceived as the particular electrode stimulated, providing information on vowel formants and high frequency fricatives. The amplitude of speech is encoded as pulse width, and is perceived as changes in the intensity of stimulation, to provide information on syllable number and stress, vowel duration, and consonant manner and voicing. The presence of high frequency information, such as is produced by high frequency fricatives, is indicated by stimulation on electrode 8 . Ongoing improvements were made to the speech encoding schemes used in the Tickle Talker speech processor (Cowan, 1991). The speech samples recorded for this study were collected from subjects using an advanced encoding scheme, which explicitly indicates presence/absence of voicing in addition to the other features.

Threshold and comfortable pulse widths for each electrode are selected by the user over the range of $10-1000 \mu \mathrm{s}$, and are then programmed into the speech processor. These levels are monitored, and adjusted as required, to ensure the comfort of the electrotactile sensation and the optimum dynamic range for each electrode. A more detailed description of the electrical parameters and device function is 
TABLE 1. Audiological details of subjects. Threshold: better ear in dB HL (ANSI, 1969).

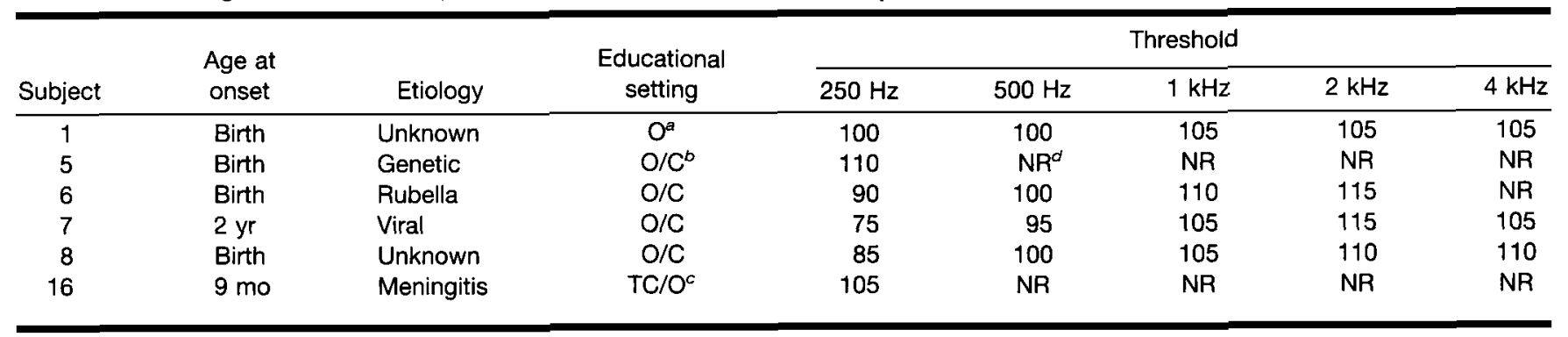

Aural/oral.

D Aural/oral with cued supplement.

$c$ Total communication and aural/oral.

${ }^{d}$ No response at audiometer limits.

presented in Blamey and Clark (1987) and Cowan, Alcántara, Blamey, and Clark (1988).

\section{Subjects}

All subjects were profoundly hearing-impaired children and suffered no other major disabilities. They were selected by their schools to join the Tickle Talker program as they were not, in the opinion of their teachers, achieving their predicted potential in speech perception and/or speech production. Six subjects for whom conversational speech samples with and without the Tickle Talker had been obtained in a single session were included. Table 1 provides audiological details of the subjects. Table 2 presents the aided thresholds for the five subjects who wore hearing aids; subject 16 was not fitted with hearing aids. Subject numbering for this study is consistent with that used in previous studies of speech perception benefits with the Tickle Talker (Cowan et al., 1990).

\section{Experience with the Device}

Table 3 indicates the age at which each subject was fitted with the Tickle Talker, and the years of device use prior to the collection of the speech samples analyzed for this study. Subjects 1, 5, 6, 7, and 8 were between 8 and 12 years of age when fitted with the Tickle Talker, while subject 16 was

TABLE 2. Monaural left and right aided hearing thresholds of subjects measured in dB SPL in free-field.

\begin{tabular}{cccccc}
\hline & \multicolumn{5}{c}{ Aided threshold (L/R) } \\
\cline { 2 - 6 } Subject & $250 \mathrm{~Hz}$ & $500 \mathrm{~Hz}$ & $1 \mathrm{kHz}$ & $2 \mathrm{kHz}$ & $4 \mathrm{kHz}$ \\
\hline 1 & $55 / 55$ & $50 / 50$ & $45 / 45$ & $50 / 65$ & $65 / \mathrm{NR}^{a}$ \\
5 & $55^{b} / 50^{b}$ & $65^{b} / 65^{b}$ & $\mathrm{NR} / \mathrm{NR}$ & $\mathrm{NR} / \mathrm{NR}$ & $\mathrm{NR} / \mathrm{NR}$ \\
6 & $55 / 55$ & $50 / 50$ & $50 / 50$ & $55 / 55$ & $\mathrm{NR} / \mathrm{NR}$ \\
7 & $55 / 50$ & $45 / 45$ & $45 / 40$ & $50 / 50$ & $55 / 55$ \\
8 & $60 / 65$ & $50 / 50$ & $40 / 45$ & $50 / 45$ & $75 / 60$
\end{tabular}

\footnotetext{
No response at $80 \mathrm{~dB}$ SPL.
}

${ }^{b}$ Vibrotactile responses only.
15 years and 3 months old when fitted with the device. Subjects 1,5 , and 6 had at least 3 years and 9 months of experience with the Tickle Talker when the speech samples were collected. The other three subjects had less than 3 years and 1 month of experience, with subject 16 being the most inexperienced with only 1 year and 6 months of device use. Subjects attended habilitation and device maintenance sessions with a research audiologist in a quiet room at their school. Details of the hierarchical phoneme, word, sentence, and conversational speech perception training program employed were reported in Galvin, Cowan, Sarant, Blamey, and Clark (1993). Although the children were occasionally encouraged to compare the tactile representation of their speech productions with those of the audiologist, the main focus of the training sessions remained speech perception, and no formal speech production training was provided. Prior to 1991 all subjects attended twice-weekly sessions of approximately 45-minute duration during the school term. Difficulties with school curriculum timetabling in 1991 necessitated a reduction in contact sessions to 30 minutes twice-weekly for subjects 7 and 8 , and 45 minutes once-weekly for subject 16. During 1992 subject 1 only attended five sessions due to the closure of her school. This subject's use of the device

TABLE 3. Device experience of subjects and their age at device fitting and speech sampling.

\begin{tabular}{cclcc}
\hline & $\begin{array}{c}\text { Date of } \\
\text { speech } \\
\text { sampling }\end{array}$ & $\begin{array}{c}\text { Age at Tickle } \\
\text { Talker fitting }\end{array}$ & $\begin{array}{c}\text { Age at speech } \\
\text { sampling }\end{array}$ & $\begin{array}{c}\text { Years of } \\
\text { device use }\end{array}$ \\
\hline 1 & $7 / 92$ & $10 \mathrm{yr} 11 \mathrm{mo}$ & $15 \mathrm{yr} 9 \mathrm{mo}$ & $4 \mathrm{yr} 10 \mathrm{mo}^{\circ}$ \\
5 & $10 / 92$ & $8 \mathrm{yr} 5 \mathrm{mo}$ & $13 \mathrm{yr} 6 \mathrm{mo}$ & $5 \mathrm{yr} 1 \mathrm{mo}^{b}$ \\
6 & $6 / 91$ & $8 \mathrm{yr}$ & $11 \mathrm{yr} 9 \mathrm{mo}$ & $3 \mathrm{yr} 9 \mathrm{mo}^{\circ}$ \\
7 & $6 / 91$ & $8 \mathrm{yr}$ & $11 \mathrm{yr} 9 \mathrm{mo}$ & $3 \mathrm{yr} 1 \mathrm{mo}^{c}$ \\
8 & $6 / 92$ & $8 \mathrm{yr} 6 \mathrm{mo}$ & $11 \mathrm{yr} 4 \mathrm{mo}$ & $2 \mathrm{yr} 10 \mathrm{mo}$ \\
16 & $11 / 91$ & $15 \mathrm{yr} 3 \mathrm{mo}$ & $16 \mathrm{yr} 9 \mathrm{mo}$ & $1 \mathrm{yr} 6 \mathrm{mo}$ \\
\hline
\end{tabular}

a 1st yr and 5 mo on analytical training program (Alcántara et al., 1990).

b 1st yr and 6 mo on analytical training program (Alcántara et al., 1990).

$c 1$ st yr on analytical training program, then 8-mo break from program (Alcántara et al., 1990). 
during this time may not have been as consistent as it was previously. Subject 5 also changed schools at the start of 1992, and used the device infrequently during this year (also the period during which she was assessed for eventual cochlear implantation). Furthermore, in the opinion of her teachers and research audiologist, this subject was a particularly inconsistent user of the device.

\section{Speech Sample Collection}

The articulation accuracy of the subjects was examined through analyses of samples of their conversational speech. Although use of connected speech sampling has been criticized on the basis of the potential for variations in the administrative conditions, test methods, materials (Markides, 1983), and verbal behavior of the examiner to produce measurable differences in language samples obtained (Cowan, Weber, Hoddinott, \& Klein, 1967; Ahmed, Reference Note 1), this sampling method was deemed to be the most suitable method to provide a variety of phoneme samples and information on co-articulation in running speech. The procedure is particularly appropriate as the aim of the study is to consider the role of tactile information in the self-monitoring of articulation in connected speech.

Conversation sampling was chosen as the method most likely to provide valid and representative samples of the children's connected speech. This was based on studies comparing language samples obtained from children through picture description and conversation which showed that unstructured conversational situations produced samples of greater quantity and complexity, with adult-child conversations being the most efficient (Longhurst \& Grubb, 1974). Other researchers have recommended the use of meaningful contexts, familiar settings, noncontrived situations and age-appropriate and motivating activities to obtain a representative speech sample (Roth \& Spekman, 1984).

Conversational sample collection was facilitated by the long-term relationship and rapport developed between the subjects and the research audiologist acting as the conversation partner. Two research audiologists were involved, one acting as the conversation partner for subjects $1,7,8$, and 16 , and the other being the partner for subjects 5 and 6 . To remove the stress of face-to-face testing, and to maintain the flow of the interaction, on-line transcription was not employed. The speech samples were recorded audio-visually using a National F2 video camera and $\mathrm{x}$ ational $180 \mathrm{~A}$ portable video recorder. Use of audio-visual recording allows repeated viewing, and has been shown to enable multiple levels of analysis of the speech samples (Roth \& Spekman, 1984), and to maximize intelligibility scores by allowing judges to consider the position of the child's articulators in their decisions (Kricos, Lesner, \& Lazarus, 1990).

Subjects $1,5,6,7$, and 8 wore their binaural hearing aids during all conversations. The subjects were not discouraged from lipreading; however, no form of manual supplement to communication was used. Two samples, one with the Tickle Talker on ("device-on") and one with the Tickle Talker off ("device-off"), were recorded in succession at each assessment. In general, the device-on speech sample was obtained first, followed immediately by the device-off sample. The device condition was reversed and the recording was concluded when the audiologist judged that the sample was large enough, or when the session time was finished. As detailed below, the initial portion of each device-on sample and each device-off sample was discarded. The speech samples used in the present study were the most recent samples recorded for each subject. The dates of sample collection are shown in Table 3.

\section{Speech Sample Transcription}

All tapes were orthographically transcribed by the audiologist who was the conversation partner for subjects $1,7,8$, and 16 . The majority of transcriptions were completed within $1 \mathrm{wk}$ of recording. After the first draft transcription, the videos were replayed twice to check the draft accuracy. The equipment used was a National $180 \mathrm{~A}$ portable video cassette recorder and a National Quintrix monitor. The final check was completed in a soundproof room using a Panasonic AG7500 video cassette recorder and a Panasonic AGA75 editing machine. Difficultto-transcribe sections were replayed up to five times to take advantage of context. The conversation partner for subjects 5 and 6 was occasionally consulted for clarification (e.g., for names of the child's siblings) during the transcription of the speech samples of these subjects.

The following were discarded from the orthographic transcriptions:

i) utterances produced while the child was laughing or yawning,

ii) muttered words,

iii) incomplete words (for example, when the child changed his/her mind in the middle of a word and used an alternative word),

iv) words over which the audiologist spoke.

The 12 orthographic transcriptions (6 subjects $\times$ 2 conditions) were then entered into the Computer Assisted Speech and Language Analysis (CASALA) program (Blamey, 1993). To ensure that the children 
were relaxed and that the flow of conversation had been established prior to the section of speech to be analyzed, the first 50 words of each transcription were discarded. The CASALA program then selected the next 100 original words from each transcription. A word was only included on its first occurrence so that the repeated and often poorly produced expressions of assent and dissent and requests for clarification used by the children were only included in the analysis once. For subject 6 in the device-on condition there were only 99 original words available for selection.

The 100 hundred words selected from each orthographic transcription were then phonemically transcribed using a narrow transcription method. The phonemic transcriptions were completed in a soundproof room, using the equipment described above. The audiologist was not blind to the device condition of the conversation being transcribed, since the same researcher had collected many of the conversational samples, and had prepared all of the orthographic transcriptions. The 12 speech samples were transcribed in random order. To balance possible changes over time in the decision criteria used by the transcriber, the first 50 words from each sample were phonemically transcribed in the determined random order, with the final 50 words from each sample being transcribed in reverse order. To assess intra-transcriber agreement the phonemic transcription of two 25 word segments, randomly chosen from the 12 orthographic transcriptions, was repeated, without reference to the first transcription, and at least 3 months after the original. To assess inter-transcriber agreement, a second researcher independently phonemically transcribed four 25word segments randomly chosen from the 12 orthographic transcriptions. This listener was blind to the device condition of each conversation.

The phonemic transcriptions of the 100 words from each speech sample were then entered into the CASALA program. The program compared the phonemic transcription of each word with the correct phonemic transcription for that word stored in CASALA. The correct phonemic transcriptions were originally obtained from The Macquarie Dictionary (Delbridge, Bernard, Blair, \& Ramson, 1987). In this way, the CASALA program calculated the percentages of total, initial, medial and final vowels, consonants, and overall phonemes that were correctly articulated in each set of one hundred words. As there were a small number of clusters in each position category, the consonants in clusters were counted individually. " 2 by 2 " contingency tables, incorporating the number of correct and the number of incorrect articulations in each condition, were then created for each device-on versus device-off
TABLE 4. Percentage of total vowels, consonants, and phonemes correctly articulated in each speech sample by the six subjects.

\begin{tabular}{|c|c|c|c|c|c|c|}
\hline \multirow[b]{2}{*}{ Subject } & \multicolumn{2}{|c|}{ Vowels } & \multicolumn{2}{|c|}{ Consonants } & \multicolumn{2}{|c|}{ Phonemes } \\
\hline & - off & -on & - off & -on & -off & -on \\
\hline 1 & 73.6 & 76.2 & 64.2 & 68.2 & 67.9 & 71.4 \\
\hline 5 & 19.6 & 18.1 & 44.7 & 41.7 & 34.7 & 32.5 \\
\hline 6 & 53.9 & 43.1 & 45.2 & 46.8 & 48.6 & 45.3 \\
\hline 7 & 37.4 & 44.8 & 42.9 & 43.1 & 40.8 & 43.7 \\
\hline 8 & 24.8 & 36.8 & 31.2 & 44.6 & 28.8 & 41.6 \\
\hline 16 & 14.6 & 27.2 & 54.9 & 58.5 & 39.2 & 46.3 \\
\hline
\end{tabular}

- off: speech sample obtained with Tickle Talker off;

-on: speech semple obtained with Tickle Talker on.

score pair. A chi-square analysis was carried out for each contingency table to assess the significance of any differences in articulation accuracy scores between the device-on and the device-off conditions. The CASALA program also calculated the incidence levels of phonological processes which operated on each subject's speech in the two conditions. This information was used to consider the improvements underlying any significant change in the number of correct articulations produced by a subject in the device-on versus the device-off condition.

\section{Results}

The intra-transcriber agreement levels calculated were $95 \%$ for a broad transcription method, and $70 \%$ for a narrow transcription method (as calculated using the method described by Shriberg and Lof (1991)). Similar calculations found inter-transcriber agreement levels of $\mathbf{8 6 \%}$ (for a broad transcription) and $76 \%$ (for a narrow transcription).

Table 4 reports the percentages of total vowels, consonants, and overall phonemes correctly articulated by the six subjects. The table lists device-on and device-off percentage correct scores for each subject in each category. Subjects 5,6 , and 7 did not demonstrate any significant $(p>0.05)$ changes in the accuracy of their articulation in the device-on condition versus the device-off condition. Subjects 1, 8 , and 16 displayed some significant improvements in articulation accuracy, and their scores are presented in more detail in Tables 5, 6, and 7, respectively.

As shown in Table 5, significant improvements ( $p$ $<0.03$ ) in device-on articulation accuracy for subject 1 occurred on initial consonants $(12.1 \%)$ and initial phonemes $(11.2 \%)$. The most common error made by this subject in the device-off articulation of initial consonants was consonant deletion. The incidence of this process was reduced when the Tickle Talker was used. The other processes acting on initial consonants (voicing, devoicing, stopping, and frica- 
TABLE 5. Percentage of total, initial, medial, and final vowels, consonants, and phonemes correctly articulated in each speech sample by subject 1 .

\begin{tabular}{|c|c|c|c|}
\hline Category & Device-off & Device-on & $\begin{array}{c}\text { Significance } \\
\text { level }\end{array}$ \\
\hline Total vowels & 73.6 & 76.2 & $\mathrm{NS}^{a}$ \\
\hline Initial vowels & 73.3 & 78.6 & NS \\
\hline Medial vowels & 68.8 & 73.3 & NS \\
\hline Final vowels & 83.8 & 84.4 & NS \\
\hline Total consonants & 64.2 & 68.2 & NS \\
\hline Initial consonants & 80.0 & 92.1 & $p<0.0182$ \\
\hline Medial consonants & 75.8 & 68.5 & NS \\
\hline Final consonants & 39.5 & 41.3 & NS \\
\hline Total phonemes & 67.9 & 71.4 & NS \\
\hline Initial phonemes & 79.1 & 90.3 & $p<0.024$ \\
\hline Medial phonemes & 70.9 & 71.6 & NS \\
\hline Final phonemes & 54.0 & 53.6 & NS \\
\hline
\end{tabular}

tion) did not occur as often as consonant deletion, but were also slightly less common in the device-on condition. Together, the reduction in these five processes contributed to a significant improvement in subject 1's articulation of initial consonants. There were very few changes in the frequency or type of phonological processes operating on subject 1's articulation of initial vowels in the device-on as compared with the device-off condition. Therefore, the improvement in initial consonants is the origin of the significant improvement in articulation of initial phonemes calculated for subject 1 .

Table 6 shows the significant improvements $(p<$ $0.04)$ in device-on articulation of total vowels (12\%),

TABLE 6. Percentage of total, initial, medial, and final vowels, consonants, and phonemes correctly articulated in each speech sample by subject 8 .

\begin{tabular}{|c|c|c|c|}
\hline Category & Device-off & Device-on & $\begin{array}{c}\text { Significance } \\
\text { level }\end{array}$ \\
\hline Total vowels & 24.8 & 36.8 & $p<0.0325$ \\
\hline Initial vowels & 35.3 & 52.9 & $\mathrm{NS}^{a}$ \\
\hline Medial vowels & 28.1 & 37.8 & NS \\
\hline Final vowels & 09.7 & 24.1 & NS \\
\hline Total consonants & 31.2 & 44.6 & $p<0.0037$ \\
\hline Initial consonants & 34.7 & 55.7 & $p<0.0036$ \\
\hline Medial consonants & 37.5 & 50.0 & NS \\
\hline Final consonants & 23.1 & 28.4 & NS \\
\hline Total phonemes & 28.8 & 41.6 & $p<0.0003$ \\
\hline Initial phonemes & 34.8 & 55.3 & $p<0.002$ \\
\hline Medial phonemes & 31.4 & 41.8 & NS \\
\hline Final phonemes & 19.3 & 27.3 & NS \\
\hline
\end{tabular}

TABLE 7. Percentage of total, initial, medial and final vowels, consonants and phonemes correctly articulated in each speech sample by subject 16 .

\begin{tabular}{|c|c|c|c|}
\hline Category & Device-off & Device-on & $\begin{array}{c}\text { Significance } \\
\text { level }\end{array}$ \\
\hline Total vowels & 14.6 & 27.2 & $p<0.0105$ \\
\hline Initial vowels & 14.8 & 33.3 & $N S^{a}$ \\
\hline Medial vowels & 16.3 & 30.5 & NS \\
\hline Final vowels & 10.0 & 13.3 & NS \\
\hline Total consonants & 54.9 & 58.5 & NS \\
\hline Initial consonants & 69.0 & 70.2 & NS \\
\hline Medial consonants & 50.0 & 66.7 & NS \\
\hline Final consonants & 43.2 & 42.2 & NS \\
\hline Total phonemes & 39.2 & 46.3 & $p<0.059$ \\
\hline Initial phonemes & 55.9 & 62.0 & NS \\
\hline Medial phonemes & 29.2 & 43.3 & $p<0.0189$ \\
\hline Final phonemes & 34.2 & 34.5 & NS \\
\hline
\end{tabular}

total consonants $(13.4 \%)$, initial consonants $(21 \%)$, total phonemes $(12.8 \%)$, and initial phonemes (20.5\%) made by subject 8 . In considering the phonological processes operating on subject 8's articulation of vowels, the main problem areas were vowel shortening, vowel reduction, nasalization, vowel elongation, and, to a lesser extent, vowel deletion. Although the incidence of vowel elongation increased when the tactile information was present, the incidence of vowel reduction and vowel deletion decreased. The reduced incidence of these processes would have contributed to the significant improvement in this subject's articulation of total vowels. In subject 8's device-off articulation of total consonants, consonant deletion, consonant backing, consonant voicing, and no sound (when the phoneme is mouthed but no sound is audible) were the most common errors, in decreasing level of incidence. All of these processes were less common in the articulation of subject 8 when the Tickle Talker was being used, and this resulted in a significant improvement in total consonant articulation. The incidence of consonant deletion, consonant voicing and consonant backing also decreased in this subject's articulation of initial consonants. These reductions contributed to the significant improvement in the articulation accuracy of initial consonants and initial phonemes shown by subject 8 .

The results presented in Table 7 show that subject 16 significantly improved $(p<0.02)$ on the articulation of total vowels $(12.6 \%)$ and medial phonemes (14.1\%) when the tactile feedback was available. Improvement of $7.1 \%$ was also noted on the articulation of total phonemes by this subject in the device-on condition (significance of $p<0.06$ ). The 
main processes which operated on the device-off articulation of vowels by subject 16 were vowel shortening, nasalization, and vowel reduction. The improvement in device-on articulation of vowels by this subject was mainly due to a reduction in vowel shortening errors on medial vowels, and fewer vowel reduction errors on initial and medial vowels. The main processes involved in the articulation of consonants by subject 16 were consonant deletion, consonant voicing, and consonant backing. The increased number of medial phonemes correctly articulated by subject 16 in the device-on condition was due to a decrease in the incidence of vowel shortening, vowel reduction and, to a lesser extent, consonant deletion, consonant voicing, and consonant backing.

\section{Discussion}

Three of the six subjects in this study demonstrated significant improvements in the accuracy of their articulation in conversation when using online tactile information provided through the Tickle Talker. These results suggest that the on-line provision of tactile information through this device may benefit the self-monitoring of articulation for some device users. It is of interest to consider the significant improvements in articulation shown by three of the subjects in relation to the speech information supplied by the Tickle Talker.

For subjects 1 and 8, who improved on the articulation of initial consonants, consonant deletion was the most common error being made, and it was decreased for both subjects when the Tickle Talker was used. The Tickle Talker provides information on consonant manner through durational and spectral cues, and specifically encodes the presence of high frequency consonants. These cues would not be readily accessible through lipreading or through the subjects' hearing aids. The two subjects may have used this information to decrease the incidence of consonant deletion in their articulation. Initial voicing was another error which subjects 1 and 8 had in common. For both of these subjects this was not a very frequent error, yet its incidence was reduced in the device-on condition. As consonant voicing is a major perceptual difficulty for children with limited aided residual hearing, the speech processing scheme used in the Tickle Talker was altered to improve the initial voicing cue provided tactually. These two subjects may have used this cue for on-line monitoring of initial consonant voicing.

Significant improvement was shown on vowel articulation by subjects 8 and 16 . For both of these subjects there was a decrease in the incidence of vowel reduction when the Tickle Talker was used.
As electrode position indicates second formant frequency, and electrode recognition is one of the easiest tasks to accomplish with the device, these two subjects may have been able to monitor their vowel production through feedback on second formant frequency. Vowel shortening was also an error that was made by subjects 8 and 16 in vowel articulation. However, the incidence of this process was only decreased when the Tickle Talker was used by subject 16 . Vowel duration is a very simple cue to perceive through the Tickle Talker and it might have been hoped that the incidence of vowel shortening may also have been decreased for subject 8 . A possible explanation is that as he received low frequency information via his hearing aids, and this was the modality with which he had the most experience, subject 8 attended to the auditory signal to discriminate vowel duration. Although he was not always able to correctly discriminate vowel duration using the auditory cue, subject 8 may have shown no device-on reduction in the incidence of vowel shortening as he was ignoring the tactile cue. Subject 16, who did not wear hearing aids, may have attended more closely to the tactile cue to vowel duration, and, therefore, the incidence of this process was reduced in this subject's device-on articulation. $\mathrm{Na}$ salization was an error subjects 8 and 16 both made, yet neither subject showed a decrease in the incidence of this process in the device-on condition. An indication of nasalization may have been provided to the subjects through altered intensity of the tactile stimulus, yet it appears that this cue was too subtle to be of use in articulation self-monitoring.

Although on-line improvements in articulation for prelingually hearing-impaired adolescents represent a very substantial and real benefit not often found in this group, only half of the subjects in this study showed significant improvements in their online articulation accuracy. It is possible that use of the Tickle Talker as a speech production training device is particularly suited to some individuals. A number of variables, such as the subjects' device-off articulation performance, their aided hearing levels, and their ability to use the tactile information in speech perception may have influenced the results.

The device-off articulation performance of the subjects may be relevant as it indicates varying scope for improvement in each child's articulation. Weisenberger and Kozma-Spytek (1991) reported that only one of three subjects using the Tacticon TC-1600 failed to produce syllables which were significantly easier to identify, or to show significant improvements on 12 parameters of speech production during tracking. The researchers suggested that the lack of recorded improvement may have been influenced by the fact that this subject's speech 
may have been considered more intelligible to begin with than that of the other children. In the present study, subject 8 , who showed the most device-on articulation improvements, had the poorest deviceoff phoneme articulation score of the six subjects (see Table 4). The device-off phoneme articulation score of subject 16 , who also showed significant articulation improvements, was worse than those of subjects 1,6 , and 7 . However, the device-off phoneme articulation score of subject 16 was better than that of subject 5 , who showed no significant device-on improvements in articulation. In addition, subject 1 , who made some significant improvements in device-on articulation, had the highest device-off phoneme articulation score. Therefore, it does not seem that the poorest articulators are necessarily the most likely users whose articulation would benefit from the on-line provision of tactile feedback through the Tickle Talker.

It is possible that the tactile information provided by the Tickle Talker may only contribute to the speech of those users not accessing a great deal of acoustic feedback in self-monitoring their articulation. Table 2 reports aided hearing thresholds to give an indication of the level of auditory information available to each subject. For subject 16 , who did not wear hearing aids, the information from the Tickle Talker would not be redundant to acoustic feedback. For this reason the on-line tactile feedback may have been more useful to this subject and resulted in significant device-on articulation improvements. This contrasts with subject 5 , who obtained only vibrotactile aided hearing thresholds, yet did not show significant device-on articulation improvements. Furthermore, although subject 8 showed significant device-on articulation improvements when using the Tickle Talker, his aided thresholds were not consistently poorer across the frequencies than those of subjects 6 and 7 , who showed no articulation improvements. However, it is of interest that on two auditory-alone administrations of the Bamford-Kowal-Bench (BKB) Sentence Test (Bench \& Bamford, 1979) subject 8 scored just $10 \%$ and $26 \%$. Similarly, although subject 1's aided hearing thresholds were not consistently poorer than those of the other subjects, an auditory-alone administration of the BKB Test resulted in a score of $0 \%$. Therefore, it may be suggested that the hearing thresholds of these two subjects do not reflect their actual poor levels of auditory discrimination. Unfortunately, auditory-alone sentence-level speech perception results are not available for subjects $5,6,7$, and 16. In summary, although the use of the tactile information from the Tickle Talker in articulation self-monitoring does not appear to be predictable when based only on a subject's aided thresholds, the
TABLE 8. Scores for the six subjects on the BKB Sentence Test.

\begin{tabular}{clllll} 
& \multicolumn{2}{c}{ Previous scores (\%) } & & \multicolumn{2}{c}{ Next scores (\%) } \\
\cline { 2 - 3 } \cline { 5 - 6 } Subject & LA & TLA & & LA & TLA \\
\hline 1 & 78 & 88 & & 68 & 86 \\
5 & 84 & 90 & & Implanted ${ }^{a}$ & \\
6 & 69 & 68 & & 76 & 90 \\
7 & 68 & 80 & & 86 & 94 \\
8 & 72 & 84 & & $26(\mathrm{~A})^{b}$ & $48(\mathrm{TA})^{b}$ \\
16 & $36(\mathrm{~L})^{c}$ & $62(\mathrm{TL})^{c}$ & & $54(\mathrm{~L})^{c}$ & $58(\mathrm{TL})^{c}$ \\
\hline
\end{tabular}

${ }^{a}$ Subject received a Mini-System 22-channel cochlear implant and was not evaluated again with the Tickle Talker.

Dubject evaluated in the auditory and tactile auditory conditions.

${ }^{c}$ Subject evaluated in the lipreading and tactile plus lipreading conditions.

Previous scores: BKB scores abtained in the evaluation prior to the collection of the speech sample; next scores: BKB scores obtained in the next evaluation after the speech samples were collected; L: lipreading, A: audition, T: Tickle Talker.

subject's access to and use of aided residual hearing in speech perception may be relevant.

The speech perception and psychophysical experiments conducted with the Tickle Talker clearly show that the device provides substantial speech feature information (Blamey \& Clark, 1987; Cowan et al., 1990, 1991). However, the extent to which individual users have utilized this information has varied. In light of this, it may be important to consider the observed benefits to speech perception provided by the Tickle Talker to the subjects of the present study. Table 8 reports speech perception scores obtained by the six subjects on the BKB Test (Bench \& Bamford, 1979) in the evaluation periods prior to and following the collection of the speech samples. Although the scores obtained by the subjects vary across the two evaluation periods, the largest improvements in perception when the Tickle Talker was used were shown by subjects 8 and 16 . On at least one evaluation, each of these subjects improved by more than $22 \%$ when using the tactile information. Subject 1 improved an average of $12 \%$ when using the Tickle Talker. Although receiving no useful auditory input, subject 5 improved only $6 \%$ when using the tactile information. As discussed previously, this child was an inconsistent user of the device, and this may partly explain the lack of improvement shown on the BKB Test. It is possible that subjects 1,8 , and 16 were more aware of and able to use the tactile information in speech production as well as in speech perception. Therefore, a subject's ability to use the tactile information in speech perception may relate to the use of this information to self-monitor articulation. This would be consistent with the finding of Weisenberger and Kozma-Spytek (1991) that the two of three 12-yearold children who showed the greatest gains in tracking rate when using the Tacticon TC- 1600 also showed the greatest improvements in speech production during tracking with the device. 
Previous studies of tactile feedback have found that some benefits to speech production are integrated into the speech of the user over time, and will not necessarily be detected by a device-on/device-off comparison. These changes to speech production may occur when the additional information is used to highlight the relevant kinesthetic or auditory information the speaker receives but does not use. Increased awareness of kinesthetic feedback was suggested when children maintained improved fundamental frequency control post-training, without the use of the feedback from the tactile device used during $6 \mathrm{hr}$ of training (Stratton, 1974). A personal communication from A. E. Geers reported in the study of Weisenberger and Kozma-Spytek (1991) argued that tactile devices may be useful in the initial acquisition of a particular skill, but are not necessarily required for its maintenance once acquired. The longer period of device use experienced by subjects 5 and 6 may have resulted in these two subjects incorporating improvements in articulation resulting from the tactile feedback into their deviceoff speech production. However, subject 1 had also received extensive experience, yet still showed significant differences in initial consonant and initial phoneme articulation in the device-on versus deviceoff comparison. Therefore, it is not possible to assume that subjects 5 and 6 may have incorporated the improvements in their articulation into their device-off speech. This would require ongoing evaluation of the children's speech over time.

As discussed, there is no single definitive rationale or factor which adequately explains the variability in improvements to articulation from use of on-line tactile feedback shown by the subjects in this study. Nevertheless, use of the Tickle Talker benefited speech production (i.e., improved articulation accuracy) in three of the adolescents. This is a very encouraging finding considering the limited number of studies which have examined the use of on-line tactile feedback in speech production by this age group, and also given the traditional difficulties encountered in improving the speech production of the older hearing-impaired child. The results support the suitability of the Tickle Talker for use in modifying or self-monitoring of the speech production of children who have not responded to more traditional techniques. To more fully explore this proposal, training with the Tickle Talker must be provided to a larger subject group of children with specific articulation difficulties. At this time it would also be useful to trial training strategies aimed specifically at increasing awareness of and use of the tactile feedback information available to maximize benefits to articulation and possibly to other aspects of speech production.

\section{ACKNowledgments:}

The authors wish to express their gratitude to the children and parents participating in the Tickle Talker clinical development program, and to the staff of St. Mary's School for HearingImpaired Children, Glendonald School for Deaf Children, Yarra Valley Anglican School and Monash Secondary College. Thanks are due to Maria Grogan for the comparison transcriptions and to the anonymous reviewers for their worthwhile comments. We also gratefully acknowledge the financial support of the Department of Industry, Technology, and Commerce and the Department of Employment, Education, and Training of the Australian Government, the National Health and Medical Research Council, the Deafness Foundation (Victoria), the George Hicks Foundation, the Ian Potter Foundation and the Australian Research Council through the award of the Human Communication and Research Center. Support for E. A. Tobey was supplied by an Academic Enhancement Award from the National Institutes of Health (R15 DC 0037) and an Australian Visiting Scholar Award from the University of Melbourne.

Address correspondence to: Karyn L. Galvin, Australian Bionic Ear and Hearing Research Institute, 384-388 Albert Street, East Melbourne, 3002, Australia.

Received January 17, 1994; accepted September 13, 1994

\section{REFERENCES}

American National Standards Institute. (1969). Specifications for audiometers (ANSI S3.6-1969). New York: ANSI.

Bench, J., \& Bamford, J. M. (1979). Speech-hearing tests and the spoken language of hearing-impaired children. London: Academic Press.

Binnie, C. A., Daniloff, R. G., \& Buckingham, H. W. (1982). Phonetic disintegration in a 5 year old following sudden hearing loss. Journal of Speech and Hearing Disorders, 47(2), 181-189.

Blamey, P. J. (1993). CASALA. In G. M. Clark \& R. S. C. Cowan (Eds.), Cooperative Research Centre for Cochlear Implant, Speech \& Hearing Research Annual Report 1992/93. Melbourne: Ellikon.

Blamey, P. J., \& Clark, G. M. (1985). A wearable multipleelectrode electrotactile speech processor for the profoundly deaf. Journal of the Acoustical Society of America, 77, 16191621.

Blamey, P. J., \& Clark, G. M. (1987). Psychophysical studies relevant to the design of a digital electrotactile speech processor. Journal of the Acoustical Society of America, 82, 116-125.

Boothroyd, A. (1984). Auditory perception of speech contrasts by subjects with sensorineural hearing loss. Journal of Speech and Hearing Research, 27, 134-144.

Cowan, P. A., Weber, J., Hoddinott, B. A., \& Klein, J. (1967). Mean length of spoken response as a function of stimulus, experimenter, and subject. Child Development, 3, 191-203.

Cowan, R. S. C. (1991). Speech feature encoding through an electrotactile speech processor. Doctoral thesis. University of Melbourne, Melbourne.

Cowan, R. S. C., Alcántara, J. I., Blamey, P. J., \& Clark, G. M. (1988). Preliminary evaluation of a multichannel electrotactile speech processor. Journal of the Acoustical Society of America, $83(6), 2328-2338$.

Cowan, R. S. C., Blamey, P. J., Galvin, K. L., Sarant, J. Z., Alcántara, J. I., \& Clark. G. M. (1990). Perception of sentences, words, and speech features by profoundly hearing-impaired children using a multichannel electrotactile speech processor. Journal of the Acoustical Society of America, 88(3), 1374-1384. 
Cowan, R. S. C., Blamey, P. J., Sarant, J. Z., Galvin, K. L., Alcántara, J. I., Whitford, L. A., \& Clark, G. M. (1991). Role of a multichannel electrotactile speech processor in a cochlear implant program for profoundly-totally deaf adults. Ear and Hearing, 12, 39-46.

Delbridge, A., Bernard, J. R. L., Blair, D., \& Ramson, W. S. (Eds.) (1987). The Macquarie dictionary. Sydney: The Macquarie Library.

Eilers, R. E., Oller, D. K., \& Vergara, K. (1989). Speech and language progress of hearing-impaired children in a systematic training program using tactual vocoders. Volta Review Monograph, 91(5), 127-137.

Galvin, K. L., Cowan, R. S. C., Sarant, J. Z., Blamey, P. J., \& Clark, G. M. (1993). Factors in the development of a training program for use with tactile devices. Ear and Hearing, 14(2), $118-127$

Geers, A. E. (1986). Vibrotactile stimulation: case study with a profoundly deaf child. Journal of Rehabilitation Research and Development, 23, 111-117.

Geers, A. E., \& Moog, J. S. (1987). Predicting spoken language acquisition of profoundly hearing-impaired children. Journal of Speech and Hearing Disorders, 52, 84-94.

Geers, A. E., \& Tobey, E. (1992). Effects of cochlear implants and tactile aids on the development of speech production skills in children with profound hearing impairment. Volta Review, 94, 135-163.

Gold, T. (1980). Speech production in hearing-impaired children. Journal of Communication Disorders, 13, 397-418.

Goldstein, M. H. Jr., \& Proctor, A. (1985). Tactile aids for profoundly deaf children. Journal of the Acoustical Society of America, 77, 258-265.

Houde, R. A., \& Levitt, H. (1980). Part VII: Speech-training aids. In H. Levitt, J. M. Pickett, \& R. A. Houde (Eds.), Sensory aids for the hearing impaired. New York: Institute of Electrical and Electronics Engineers.

Kricos, P., Lesner, S., \& Lazarus, G. (1990). Influence of visual information on speech assessment with hearing-impaired children. Volta Review, 92(5), 213-222.

Longhurst, T. M., \& Grubb, S. (1974). A comparison of language samples collected in four situations. Language Speech and Hearing Services in Schools, 5, 71-78.

Lynch, M. P., Oller, D. K., \& Eilers, R. E. (1989). Portable tactile aids for speech perception. Volta Review Monograph, 91(5), 113-126.

Markides, A. (1983). The speech of hearing-impaired children. Manchester: Manchester University Press.

McGarr, N. S., Head, J., Friedman, M., Behrman, A. M., \& Youdelman, K. (1986). The use of visual and tactile sensory aids in speech production training: A preliminary report. Journal of Rehabilitation Research and Development, 23(1), 101-109.

McGarr, N. S., \& Osberger, M. J. (1978). Pitch deviances and intelligibility of deaf speech. Journal of Communication Disorders, 11, 237-247.

Nickerson, R. S., \& Stevens, K. N. (1973). Teaching speech to the deaf: Can a computer help? Institute of Electrical and Electron- ics Engineers Transcripts of Audio and Electroacoustics, AU. $21,445-455$.

Oller, D. K., Eilers, R., Vergara, K., \& LaVoie, E. (1986). Tactual vocoders in a multisensory program training speech production and reception. Volta Review, 88, 21-36.

Reed, C. M., Durlach, N. I., Delhorne, L. A., Rabinowitz, W. M., \& Grant, K. W. (1989). Research on tactual communication of speech: Ideas, issues, and findings. Volta Review Monograph, 91(5), 65-78.

Richardson, L. M., Busby, P. A., Blamey, P. J., Dowell, R. C., \& Clark, G. M. (1993). The effects of auditory feedback from the Nucleus cochlear implant on the vowel formant frequencies produced by children and adults. Ear and Hearing, 14(5), 339-349.

Roth, F. P., \& Spekman, N. J. (1984). Assessing the pragmatic abilities of children: Part 2. Guidelines, considerations, and specific evaluation procedures. Journal of Speech and Hearing Disorders, 49, 12-17.

Seligman, P. M. (1987). Speech-processing strategies and their implementation. Annals of Otology, Rhinology, and Laryngol ogy, 96(1), 71-73.

Shriberg, L. D., \& Lof, G. L. (1991). Reliability studies in broad and narrow phonetic transcription. Clinical Linguistics and Phonetics, 5(3), 225-279.

Stark, R., \& Levitt, H. (1974). Prosodic feature perception and production in deaf children. Journal of the Acoustical Society of America, 55, S23.

Stratton, W. D. (1974). Intonation feedback for the deaf through a tactile display. Volta Review, 76, 26-35.

Svirsky, M., Lane, H., Perkell, J. S., \& Wozniak, J. (1992). Effects of short-term auditory deprivation on speech production in adult cochlear implant users. Journal of the Acoustical Society of America, 92(3), 1284-1300.

Tobey, E. A., Angelette, S., Murchison, C., Nicosia, J., Sprague, S., Staller, S. J., Brimacombe, J. A., \& Beiter, A. L. (1991). Speech production performance in children with multichannel cochlear implants. American Journal of Otology, 12(Suppl.), 165-173.

Waldstein, R. S. (1990). Effects of postlingual deafness on speech production: Implications for the role of auditory feedback. Journal of the Acoustical Society of America, 88(5), 2099-2114.

Weisenberger, J. M. (1989). Tactile aids for speech perception and production by hearing-impaired people. Volta Review Monograph, 91(5), 79-100.

Weisenberger, J. M., \& Kozma-Spytek, L. (1991). Evaluating tactile aids for speech perception and production by hearingimpaired adults and children. American Journal of Otology, 12(Suppl.), 188-200.

\section{Reference Note}

1. Ahmed, S. E. (1973). Linguistic analysis of children's speech: Effects of stimulus media on elicited samples. Unpublished master's thesis. Kansas State University, Kansas. 


\section{University Library}

\section{- M M N E R VA A gateway to Melbourne's research publications}

Minerva Access is the Institutional Repository of The University of Melbourne

\section{Author/s:}

Galvin, Karyn L.;Cowan, Robert S. C.;Sarant, Julia Z.;Tobey, Emily A.;Blamey, Peter J.;Clark, Graeme M.

Title:

Articulation accuracy of children using an electrotactile speech processor

Date:

1995

\section{Citation:}

Galvin, K. L., Cowan, R. S. C., Sarant, J. Z., Tobey, E. A., Blamey, P. J., \& Clark, G. M. (1995). Articulation accuracy of children using an electrotactile speech processor. Ear and Hearing, 16, 209-219.

Persistent Link:

http://hdl.handle.net/11343/27454 